\title{
Los nerds de la política bajo la lupa Reseña de The Rise of Nerd Politics: Digital Activism and Political Change, de John Postill (2018)
}

\author{
Roberto Bustamante Vento \\ Instituto para la Sociedad de la Información \\ roberto.bustamante@gmail.com \\ https://doi.org/10.1880o/conexion.202002.010
}

En las últimas décadas, hemos sido testigos de una serie de fenómenos políticos globales en los que las llamadas redes sociales o servicios de medios sociales o social media han intervenido. Las protestas en Egipto, España, Estados Unidos y también en el Perú son un ejemplo. La primera mirada, la de los medios de comunicación, se centra siempre en el uso de la última herramienta de moda: en su momento, Facebook; luego, Twitter, Instagram; y, ahora, TikTok.

Pero ¿esto es así siempre? ¿No será posible tratar de observar bajo la superficie y encontrar, más bien, una movilidad de actores, organizados o no, que saben hackear al sistema mediático de una forma que las viejas generaciones no conocen? Esa parece ser la pregunta central de John Postill en su libro The Rise of Nerd Politics: Digital Activism and Political Change [El surgimiento de las políticas nerds: activismo digital y cambio político] (2018). Es un trazo de un proceso que viene desde inicios de la década de los ochenta y que toma fuerza desde los destapes de Wikileaks y el Cablegate.

Lo de Postill es, ante todo, un estudio etnográfico, enmarcado en lo que diversos autores han venido llamando etnografía digital (Pink et al., 2015), en el que a la observación participante se le suma también el estar allí - para usar un concepto del clásico libro El antropólogo como autor, de Clifford Geertz (1989)-. Postill está allí con las organizaciones de derechos digitales de Madrid y Barcelona, está allí en Indonesia, está allí en las reuniones de RightsCon, pero también está allí en los foros de discusión, en las listas de correos, en los blogs, en los comentarios de YouTube. El activismo de estos nerds de la política no se da solamente 
en vivo - de modo presencial-, sino también en múltiples espacios y de diferentes modos.

¿Cuál es el principal hallazgo de Postill? La existencia de un conjunto de activistas globales en torno a los derechos digitales, que operan tanto en el interior como en el exterior de distintas protestas que se han dado en el mundo - la del 15M español es el objeto de investigación de Postill-. ¿Son hackers en el sentido estricto? ¿Expertos en informática que prestan sus servicios a la protesta, como la figura clásica del intelectual orgánico? De ninguna forma. Pueden ser expertos en ciencias de la computación, como también profesionales que saben manejarse en el lenguaje de los social media, que saben crear contenidos que alimentan las protestas; son actores que sirven de puente entre los viejos operadores políticos y los nuevos actores en las calles. Tienen una particular forma de ver la política: como un sistema, que, por lo tanto, puede ser mejorable o hackeable. Esto puede ser también una desventaja, ya que puede implicar no ver las distintas formas que tienen los subalternos para operar dentro de los Estados y del sistema político en general (Pajuelo Teves, 2007).

Si bien el libro de Postill se ubica dentro del debate reciente planteado también por autoras como Gabriella Coleman (2015) y Zeynep Tufekci (2017/2018), en el que la acción política y las tecnologías digitales no son vistas ni como contrapuestas ni como dos fenómenos causa-efecto, sino, más bien, como fenómenos hibridados - esto es, imbricados mutuamente, donde no se puede explicar uno sin el otro-, cabe la pregunta sobre la extrapolación del fenómeno de los nerds de la política en ámbitos del sur global. ¿Existen los nerds de la política en países como los del centro andino? ¿No son acaso las tácticas llamadas armas de los débiles (Scott, 1987) formas que preceden a las de los nerds de la política? ¿Cuáles serían las nuevas armas de los débiles en tiempos de tecnologías digitales? ¿Cuáles serían las relaciones que se construirían entre estos grupos de nerds de la política con movimientos sociales indígenas en el Perú, Bolivia y Ecuador?

Para los estudios de la comunicación, el aporte del libro es permitirnos entender que el uso de los medios digitales, de Twitter, Facebook, TikTok o lo que las nuevas generaciones usen, no ocurre por fuera de las acciones políticas. Y quizá comprender de ese modo las nuevas formas 
del lenguaje de la protesta, y sus límites y posibilidades. Si miramos, por ejemplo, las últimas protestas callejeras en el Perú -las marchas contra el fujimorismo en el año 2011, las protestas contra la denominada ley pulpín o las movidas callejeras contra el régimen de Merino-, tal vez entendamos que hay mucho más que anarquía o falta de liderazgos, y que, más bien, los liderazgos han ido cambiando en un proceso que no es nuevo, sino cambiante desde hace ya diez años o más.

\section{REFERENCIAS}

Coleman, G. (2015). Hacker, hoaxer, whistleblower, spy: The many faces of Anonymous. Verso.

Geertz, C. (1989). El antropólogo como autor. Ediciones Paidós.

Pajuelo Teves, R. (2007). Reinventando comunidades imaginadas. Movimientos indígenas, nación y procesos sociopolíticos en los países centroandinos. Instituto Francés de Estudios Andinos; Instituto de Estudios Peruanos.

Pink, S., Horst, H., Postill, J., Hjorth, L., Lewis, T. y Tacchi, J. (2015). Digital ethnography: Principles and practice. SAGE Publications Ltd.

Postill, J. (2018). The rise of nerd politics: Digital activism and political change. Pluto Press. https://www.plutobooks.com/9780745399836/the-rise-ofnerd-politics/

Scott, J. C. (1987). Weapons of the weak: Everyday forms of peasant resistance. Yale University Press.

Tufekci, Z. (2018). Twitter and tear gas: The power and fragility of networked protest. Yale University Press. (Trabajo original publicado en 2017) 